\title{
Isolation and characterization of putative Pseudobutyrivibrio ruminis promoters
}

Correspondence

Tobias Schoep

tdschoep@cyllene.uwa.edu.au

Received 28 January 2007

Revised 1 June 2007

Accepted 5 June 2007
Tobias D. Schoep ${ }^{1} \dagger$ and Keith Gregg ${ }^{2}$

\author{
${ }^{1}$ Murdoch University, Western Australian State Agricultural Biotechnology Centre (SABC), School \\ of Biological Sciences and Biotechnology, South St, Murdoch, 6150 Perth, Australia \\ ${ }^{2}$ Curtin University, Biomedical Sciences, Kent Street, Bentley, 6845 Perth, Australia
}

\section{INTRODUCTION}

DNA binding specificity of bacterial RNA polymerase and the rate of transcription are largely dictated by the sequence of the upstream (UP) element (Estrem et al., 1998), and -10 and -35 motifs, which are common to most bacteria. However, atypical aspects of transcription initiation are still being identified in prokaryotes (Bayley et al., 2000; Gaal et al., 2001; Weiner et al., 2000). Novel structural properties of DNA are also being reported, but their effects on gene expression remain unknown (Petersen et al., 2003; Vanet et al., 2000; Vogel et al., 2003).

Pseudobutyrivibrio ruminis (previously classified as Butyrivibrio fibrisolvens) is present in the rumen (Kopecny et al., 2003) and gastrointestinal tract of some animals. Butyrivibrio-like organisms may account for as much as

tPresent address: University of Western Australia, Microbiology and Immunology M502, Helicobacter pylori Research Laboratory, Stirling Highway, Crawley, 6009 Perth, Australia.

Abbreviations: GUS, $\beta$-glucuronidase; HEX, hexachlorofluorescein; MCS, multiple cloning site; RT-qPCR, reverse transcription quantitative PCR.

The GenBank/EMBL/DDBJ accession numbers for the promoter 6, promoter 10, promoter 18, promoter 46, pBGT, promoter 38 and pBK6 sequences of Pseudobutyrivibrio ruminis are D0841994-D0842000.

A supplementary figure showing the relationships between the $16 \mathrm{~S}$ rDNA sequence of Pseudobutyrivibrio ruminis strain $0 / 10$ and closely related species is available with the online version of this paper.
$24-30 \%$ of culturable bacteria from the rumen (Forster et al., 1996), although individual species may constitute much lower proportions of total bacterial numbers (Kobayashi et al., 2000). These bacteria are important for projects that aim to alter rumen function using genetically modified bacteria (Brooker et al., 1989; Gregg et al., 1987, 1994, 1998; Gregg \& Sharpe, 1991; Mackie \& White, 1990; Rogers, 1990; Smith \& Hespell, 1983; Teather, 1985; Teather \& Forster, 1998). Understanding their transcriptional regulation is essential for controlling the expression of foreign genes within the rumen. Molecular mechanisms governing transcription initiation in P. ruminis and closely related species remain poorly understood. To date, only four promoters have been studied using transcriptional analysis in their species of origin: the flaA and $f l a B$ promoters in P. ruminis OR77 (Beard et al., 2000), the Pseudobutyrivibrio sp. OB156 thl promoter (Asanuma et al., 2003), and the rep promoter in B. fibrisolvens Bu49 (Beard et al., 2000; Hefford et al., 1997). B. fibrisolvens Bu49 is closely related to $P$. ruminis, but may be more appropriately classified as Clostridium proteoclasticum (Dr Jan Kopecny, Institute of Animal Physiology and Genetics, Czech Academy of Sciences, personal communication). Phylogenetic classification of Butyrivibrio-like microorganisms is still in progress.

The aim of this study was to identify consensus DNAbinding motifs for RNA polymerase in P. ruminis. For the purpose of this study DNA fragments isolated from $P$. 
ruminis shown to transcribe a plasmid-borne gene are referred to as promoters. However, these promoters were not shown to initiate transcription from the genome and remain putative promoters in this context.

\section{METHODS}

Bacterial culture, strains and plasmids. $P$. ruminis strains $0 / 10$ and OR38 were cultivated in rumen fluid medium (Klieve et al., 1989) at $39^{\circ} \mathrm{C}$ and transformed by electroporation (Beard et al., 1995). Escherichia coli strain PMC112 (Gibson, 1984) was grown in LuriaBertani (LB) medium at $37^{\circ} \mathrm{C}$ and also transformed by electroporation (Dower et al., 1988). Plasmid DNA was extracted from E. coli and P. ruminis using the Wizard Plus SV Minipreps DNA purification system; chromosomal DNA was extracted from $P$. ruminis as described previously (Woods et al., 1989). E. coli transformants were selected with ampicillin $\left(100 \mu \mathrm{g} \mathrm{ml}^{-1}\right)$ or kanamycin $\left(30 \mu \mathrm{g} \mathrm{ml}^{-1}\right)$ and $P$. ruminis transformants were selected with erythromycin $\left(100 \mu \mathrm{g} \mathrm{ml}^{-1}\right)$.

P. ruminis cultures were prepared as follows. A $2.5 \%(\mathrm{v} / \mathrm{v})$ inoculum from a frozen glycerol stock was used to start a culture that was grown for approximately 2 days. From this culture, a $2.5 \%(\mathrm{v} / \mathrm{v})$ inoculum was added to pre-warmed medium to create a starter culture. After approximately $20 \mathrm{~h}$ growth, a $2.5 \%(\mathrm{v} / \mathrm{v})$ inoculum was added to prewarmed medium, and the culture was grown for $6-10 \mathrm{~h}$ before harvesting.

Construction of promoter rescue plasmid pBK6. The construction of plasmid pBK6 is shown in Fig. 1. In summary, the ampicillin resistance gene was removed from $\mathrm{pBHE}$ and replaced with the kanamycin resistance gene from pUK21. A ribosome-binding site (RBS) was inserted upstream of the erythromycin resistance gene, ermAM (pBK2). To avoid read-through transcription from other promoters, a fragment containing the transcription terminator of bacteriophage T4D was inserted upstream of the promoter insertion point (pBK5). Finally, a multiple cloning site (MCS) was inserted downstream of the T4 terminator, upstream of the RBS, to generate plasmid pBK6.

Construction of promoter reporter plasmid pBGT. The construction of plasmid pBGT is shown in Fig. 2. Plasmid pBK2 was ligated to the gusA gene from pFUS1 (Reeve et al., 1999) to produce plasmid pBG. The PstI/NdeI fragment of pBK6 that contains the T4 terminator and MCS was ligated to the major fragment of similarly digested $\mathrm{pBG}$ to produce $\mathrm{pBGT}$.

Construction of $\boldsymbol{P}$. ruminis candidate promoter library. Chromosomal DNA from $P$. ruminis was partially digested with Sau3AI, and fragments of 400-800 bp were purified from agarose gel using the UltraClean 15 kit (Mo Bio Laboratories). Fragments were ligated to BamHI-cut and dephosphorylated forms of plasmids pBK5 or pBK6. Plasmids were transferred to E. coli and recombinants were selected by PCR-based screening.

Recombinant plasmid pBK5 or pBK6, containing chromosomal DNA fragments from $P$. ruminis, were pooled into groups of four and transferred to $P$. ruminis. Plasmids that contained active promoters conferred the erythromycin-resistant $\left(\mathrm{Erm}^{\mathrm{r}}\right)$ phenotype. Promoter 38 was isolated similarly from $P$. ruminis OR38 using promoter rescue plasmid pBHE (Beard et al., 2000). Promoter-active DNA fragments were excised and ligated into pBK6.

Confirmed promoter sequences were excised from pBK6 using XhoI and $\mathrm{NdeI}$ and were ligated to $\mathrm{XhoI} / \mathrm{NdeI}$-digested pBGT to measure transcription and translation levels.

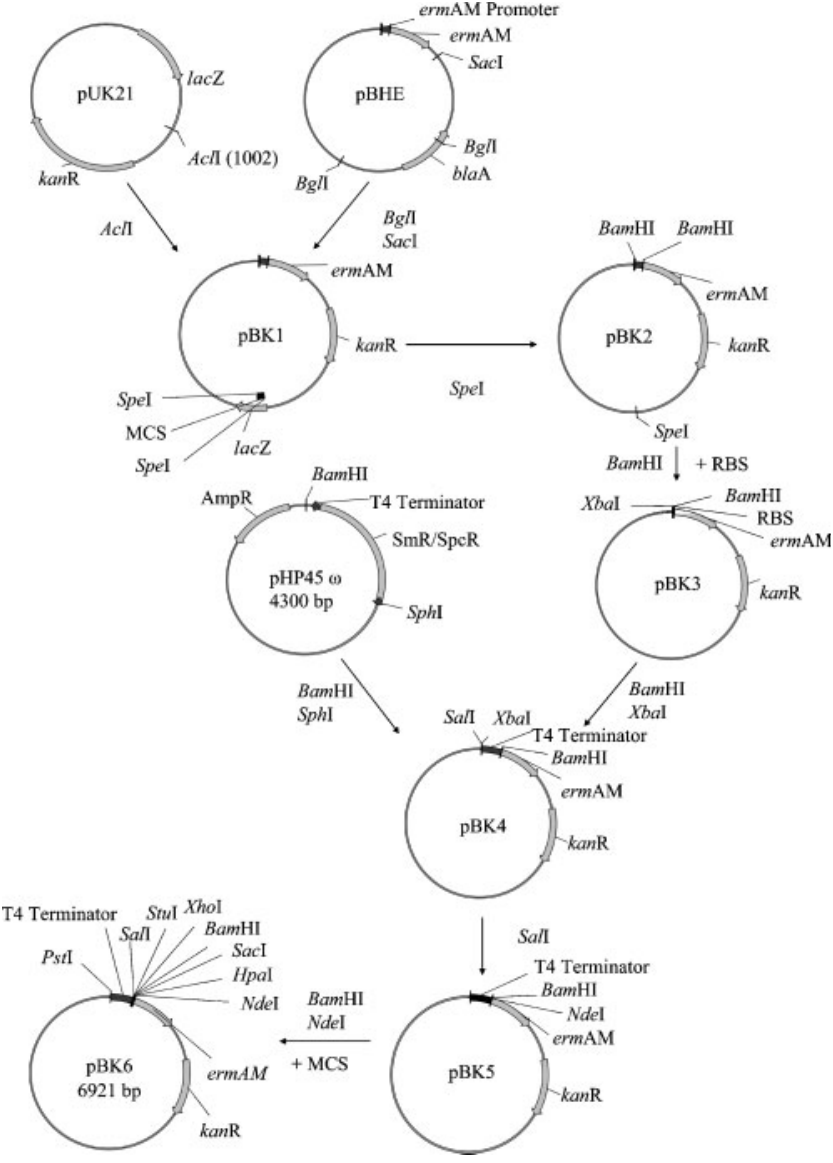

Fig. 1. Incorporation of the kanamycin resistance gene into $\mathrm{PBHE}$. The pUC118 segment of pBHE was removed using Bgll and Sacl. The resulting fragments were end-filled using DNA polymerase I Klenow fragment and the remainder of pBHE was ligated to pUK21, which had been digested with $A c / l$ and end-filled. The pUK21 multiple cloning site (MCS) was excised with Spel, and the remaining $6.8 \mathrm{~kb}$ fragment circularized by ligation. A ribosomebinding site (RBS) was synthesized as two complementary oligonucleotides RBSF and RBSR (Table 1), which were annealed to produce a double-stranded fragment with BamHI-compatible overhanging termini. This was inserted into the BamHI site downstream of the insertion site for potential promoters and directly upstream of the promoter selection gene (ermAM) to produce plasmid pBK3. The gene 32 transcription/translation terminator (T4 terminator of bacteriophage T4D; Prentki \& Krisch, 1984) was excised from plasmid pHP $45 \Omega$ (Prentki \& Krisch, 1984), digested with Sphl, end-filled and digested with BamHI. This was inserted upstream of the promoters' insertion site. Plasmid pBK3 was similarly prepared, although initially cleaved with $X b a l$ and then $B a m H I$. DNA containing the terminator and backbone of $\mathrm{pBK} 3$ were ligated to produce pBK4. The Sall site of pBK4 was inactivated by cleavage of the Sall site, end-filled and self-ligated to produce plasmid pBK5. To insert a MCS downstream of the transcription terminator and upstream of the promoter selection gene (ermAM), pBK5 was digested with $\mathrm{Ndel}$ and $\mathrm{BamHI}$ and ligated with the MCS, which was constructed as complementary oligonucleotides MCSF and MCSR to provide cleavage sites for Ndel and BamHI. The final construct was termed pBK6. 

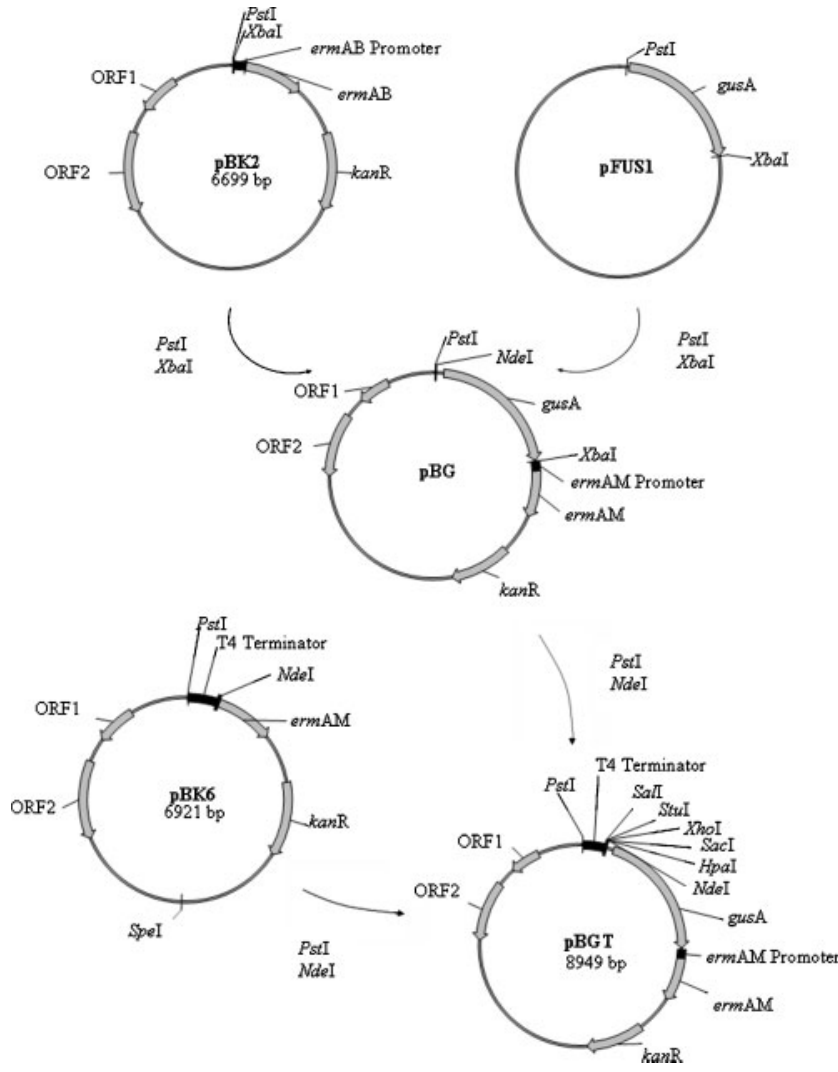

Fig. 2. Vector $p B G$ was constructed with the promoterless gus $A$ gene located directly downstream of a promoter insertion site. Plasmids pBK2 and pFUS1 (Reeve et al., 1999) were digested with Pstl and Xbal. Dephosphorylated pBK2 plasmid backbone and the section of pFUS1 containing the gus $A$ gene were ligated together. Vectors $\mathrm{pBK} 6$ and $\mathrm{pBG}$ were digested with Pstl and Ndel. The backbone fragment of $\mathrm{pBG}$ was ligated to the T4 transcriptional terminator-MCS fragment from $\mathrm{pBK} 6$ to produce the promoter reporter plasmid pBGT.

RNA extraction. RNA was extracted from E. coli and P. ruminis using hot, acidic phenol (Kalmokoff et al., 1999). E. coli were grown to $\mathrm{OD}_{600} \sim 1$. P. ruminis cultures were harvested after growth for 6-10 h. To reduce the amount of extracellular polysaccharide in the extracts, $P$. ruminis were rinsed with diethyl pyrocarbonate (DEPC)-treated, chilled saline $(0.89 \%, \mathrm{w} / \mathrm{v}, \mathrm{NaCl})$. RNA was stored at $-80{ }^{\circ} \mathrm{C}$, in ethanol or RNase-free water. All solutions were treated with $0.1 \%$ $(\mathrm{v} / \mathrm{v})$ DEPC to inactivate nucleases. Where necessary, to remove residual DNA, samples were treated with RQ1 RNase-free DNase as described by the manufacturer (Promega).

DNA sequencing and PAGE. For calibration and primer extension studies hexachlorofluorescein (HEX)-labelled DNA fragments were ethanol precipitated with Big Dye V3.1 or rhodamine-based sequencing products. Sequencing was by the dideoxy-dye-termination process (Applied Biosystems Sequencing Technical Manual; Perkin Elmer). The precipitate was redissolved in water and analysed on an ABI PRISM 377XL sequencer. Using ABI 377 sequencer software, HEX-labelled product was represented by a green peak, the same as for adenosine. To ensure the differentiation of HEX-labelled product from a coinciding adenosine base, at least two dilutions of this product were analysed.
Calibration of primer extension method. The migration of HEXlabelled DNA standards was calibrated against that of rhodamine- or Big Dye-based TSS1-primed sequencing products. HEX-labelled PCR products of precisely known size were amplified from pUC18 using Pf $x$ DNA polymerase and HEX-labelled primer TSS1 in combination with primers Std1 (product size $100 \mathrm{bp}$ ), Std2 (200 bp), Std3 (300 bp), Std4 (391 bp), Std5 (472 bp) or Std6 (595 bp; Table 1).

Primer extension. Extension reactions $(30 \mu \mathrm{l})$ contained 5-35 $\mu \mathrm{g}$ of total bacterial RNA, $3 \mu \mathrm{M}$ HEX-labelled primer, 10 units AMV reverse transcriptase and the manufacturer's buffer (Promega), $1.7 \mathrm{mM}$ each of the four deoxynucleotide triphosphates and 20-40 units RNasin RNase inhibitor (Promega), and were incubated at $42{ }^{\circ} \mathrm{C}$ for $60 \mathrm{~min}$. Primer extension products were purified using the UltraClean 15 kit (Mo Bio Laboratories), redissolved in water and coelectrophoresed with sequencing products, primed using an unlabelled version of the extension primer.

Primer extension analysis of the blaA promoter used primers complementary to three locations within blaA in pUC18 (Brosius et al., 1982). HEX-labelled primers TSS1, TSS2 and TSS3 (Table 1) were used to initiate reverse transcription with the primers' $5^{\prime}$ terminal bases at positions 118, 269 and $519 \mathrm{bp}$ downstream of the blaA transcription start site respectively.

Primer extension reactions were performed on RNA extracted from $P$. ruminis containing pBK6 recombinants harbouring active promoters. Reverse transcription and rhodamine-based sequencing reactions were primed using HEX-labelled TS1 and unlabelled TS1 respectively. Correcting observed primer extension product sizes using the equation described in Table 2 identified transcription start sites.

Quantitative $\boldsymbol{\beta}$-glucuronidase (GUS) assay. $P$. ruminis cells were harvested after $6 \mathrm{~h}$ growth, resuspended in saline, and adjusted to $\mathrm{OD}_{600} 2.0$. Aliquots were snap-frozen at $-80{ }^{\circ} \mathrm{C}$ for use in GUS and protein assays.

GUS assays were performed as described by Reeve et al. (2002), with the exceptions that $10 \mu \mathrm{l} 17.5 \mathrm{mg} \mathrm{ml}^{-1} p$-nitrophenyl $\beta$-D-glucuronide (pNPG) was added to start the reaction and absorbance measurements were taken at $405 \mathrm{~nm}$ every $2 \mathrm{~min}$ for $2.5 \mathrm{~h}$ using a Bio-Rad model 3550 -UV microplate reader pre-warmed to $37^{\circ} \mathrm{C}$.

Table 1. Oligonucleotides

\begin{tabular}{|ll|}
\hline Name & \multicolumn{1}{c|}{ Nucleotide sequence $\left(\mathbf{5}^{\prime} \mathbf{- 3}^{\prime} \mathbf{)}\right.$} \\
\hline MCSF & GATCGTCGACAGGCCTCGAGGATCCGAGCTCGTT- \\
& AACA \\
MCSR & TATGTTAACGAGCTCGGATCCTCGAGGCCTGTCG- \\
& AC \\
RBSF & GATCCATATGAAGAGGAGA \\
RBSR & GATCTCTCCTCTTCATATG \\
SBRF & ATCAGGAAGTGATGGAGCAT \\
SBRR & TTGTTCACACAAACGGTGAT \\
Std1 & ATAACACTGCGGCCAACTTA \\
Std2 & TCTCAGAATGACTTGGTTGA \\
Std3 & ACGTTTTCCAATGATGAGCA \\
Std4 & AAGATGCTGAAGATCAGTTG \\
Std5 & ATTTCCGTGTCGCCCTTATT \\
Std6 & ATGTGCGCGGAACCCCTATT \\
TSS1 & CGATCAAGGCGAGTTACATG \\
TSS2 & ATACCGCGCCACATAGCAGA \\
TSS3 & CAGCGTTTCTGGGTGAGCAA \\
\end{tabular}


Table 2. Comparison between actual and observed length of HEX-labelled PCR products based on electrophoretic comigration with rhodamine- or Big Dye-based sequencing products

These results allowed the derivation of equations to correct the observed size of HEX-labelled reverse transcripts. 1 (rhodaminebased): $y=0.9894 x+0.1221 ; 2$ (Big Dye-based): $y=0.9821 x+5.836$, where $x=$ observed size and $y=$ corrected size of HEX-labelled DNA molecules.

\begin{tabular}{|lccc|}
\hline $\begin{array}{l}\text { HEX- } \\
\text { labelled } \\
\text { primer }\end{array}$ & $\begin{array}{c}\text { Predicted length } \\
\text { of HEX-labelled } \\
\text { DNA (nt) }\end{array}$ & $\begin{array}{c}\text { Observed } \\
\text { migration } \\
\text { (rhodamine- } \\
\text { based) }\end{array}$ & $\begin{array}{c}\text { Observed } \\
\text { migration } \\
\text { (Big Dye- } \\
\text { based) }\end{array}$ \\
\hline Std1 & 100 & 101 & 95.5 \\
Std2 & 200 & 202 & 198 \\
Std3 & 300 & 303 & 300 \\
Std4 & 391 & 395 & 392 \\
Std5 & 472 & 477 & 474.5 \\
\hline
\end{tabular}

Reverse transcription quantitative PCR (RT-qPCR). Quantification of plasmid copy number and of plasmid-derived transcript numbers used the Finnzymes DyNAmo SYBR GREEN qPCR kit and the PE Applied Biosystems International Prism-7700 Sequence Detection System 1.7. Plasmid copy numbers were measured in the cultures from which RNA was extracted for RTqPCR studies. Bacteria were resuspended in saline and adjusted to $\mathrm{OD}_{600}$ 4.0. Aliquots were snap-frozen at $-80{ }^{\circ} \mathrm{C}$ for use in protein assays and plasmid extraction.

A two-step RT-qPCR method was used to measure gusA transcript levels in P. ruminis. Total RNA was extracted from P. ruminis cultures after $6 \mathrm{~h}$ growth, diluted to $1 \mu \mathrm{g} \mu \mathrm{l}^{-1}$, treated with DNase (Promega) and $0.5 \mu \mathrm{g}$ was added to a $25 \mu \mathrm{l}$ reverse transcription reaction. Reactions contained $0.2 \mu \mathrm{M}$ primer SBRR (Table 1), Stratascript reaction buffer, $0.2 \mathrm{mM}$ of each dNTP, $10 \mathrm{U}$ RNasin and $50 \mathrm{U}$ Stratascript reverse transcriptase. Reactions were incubated for $1 \mathrm{~h}$ at $42{ }^{\circ} \mathrm{C}$ and $2 \mu \mathrm{l}$ of the mixture was added to each qPCR reaction.

Primers for RT-qPCR were designed as described by Bustin (2000), using the online primer design program Primer3 (Misener \& Krawetz, 2000), and melting temperatures were calculated using the online Oligonucleotide Properties Calculator (http://www.basic.northwestern.edu/biotools/oligocalc.html), based on the nearest neighbour method (Breslauer et al., 1986). To measure plasmid and transcript copy numbers, primers SBRF and SBRR were used to amplify a section of the gusA gene. qPCR was performed as described by the kit manufacturer (Dynamo SYBR green qPCR kit instruction manual, Finnzymes) using 40 cycles at $95{ }^{\circ} \mathrm{C}$ for $15 \mathrm{~s}, 60{ }^{\circ} \mathrm{C}$ for $20 \mathrm{~s}, 72{ }^{\circ} \mathrm{C}$ for $8 \mathrm{~s}$, and $80{ }^{\circ} \mathrm{C}$ for $5 \mathrm{~s}$. Data were acquired at the last step of each cycle. Results were analysed using Sequence Detector V1.7 software (Applied Biosystems). Baseline start and stop values were 3 and 6 respectively. Threshold value was defined as 0.023 . Quantification of transcript was calculated from $C_{\mathrm{T}}$ values (number of cycles required for a detectable signal) using a standard curve derived from spectrophotometrically measured concentrations of plasmid pBGT.

Measuring protein concentration. Protein concentration was measured by the BCA protein assay kit (Pierce) microtitre plate protocol, using a Bio-Rad model 3550-UV microplate reader $(595 \mathrm{~nm})$ and a standard curve constructed using BSA.
Phylogenetic analyses. Phylogenetic analyses were performed as described by Kopecny et al. (2001). To classify P. ruminis 0/10, 16S rRNA sequences from GenBank and EMBL were analysed using CLUSTAL_X (Thompson et al., 1997) and PHYLIP (Felsenstein, 1989). Sequence data for distance matrices were bootstrapped using SEQBOOT (resampled 1000 times). The DNADIST program was used to analyse distances using the Kimura-Nei method (Kimura, 1980) with the following settings: transition : transversion ratio $=2.0$, empirical base frequencies, and coefficient of variation 1 . Trees were produced from distance matrices using the neighbour-joining method (Saitou \& Nei, 1987) and a consensus tree was generated using CONSENSE (Felsenstein, 1989). Bar: 10 substitutions per 100 nt. A consensus tree was drawn using the online program Phylodendron.

Computational analyses of DNA and protein sequences. Nucleotide and amino acid sequences were compared to those in GenBank using BLAST analysis (Tatusova \& Madden, 1999). Promoter sequences were searched for transcription factor binding sites using the Tfsitescan online analysis form (http://www.ifti.org/cgi-bin/ifti/ Tfsitescan.pl) and the object-orientated transcription factor database tfsites (Ghosh, 1998, 2000). To identify consensus sequences among promoters, those in which transcription start sites have previously been mapped, including B. fibrisolvens Bu49 rep (Hefford et al., 1997), Pseudobutyrivibrio sp. OR77 flaA (Beard et al., 2000) and flaB (Kalmokoff et al., 2000), Pseudobutyrivibrio sp. OB156 thl (Asanuma et al., 2003), and those isolated in this study, were examined using the program MEME (Bailey \& Gribskov, 1998). Regions extending from -200 to $+100 \mathrm{bp}$ were examined. Due to the lack of available sequence, promoters 46 and flaB were examined between -200 and +26 and -152 and +100 respectively.

Statistical analyses. Results from RT-qPCR and GUS assays were analysed using the two-tailed Student's $t$ test. ANOVA (Box et al., 1978) was used to ensure comparable copy numbers among different constructs. Grouping of promoter activities was determined using the Tukey-Kramer honestly significant difference (HSD) comparisons of means test. For all tests it was assumed that the populations were normal and variances were equal.

\section{RESULTS}

\section{Phylogenetic classification of $\boldsymbol{P}$. ruminis strain 0/10}

P. ruminis $0 / 10$ was isolated from sheep rumen by Linda Kennedy (Murdoch University, Western Australia) on RF agar. Classification was based on morphology (i.e. a narrow, curved rod with a polar flagellum, approximately $1-1.5 \mu \mathrm{m}$ in length) and on $97 \%$ nucleic acid identity to $16 \mathrm{~S}$ rRNA sequences of previously studied species of Pseudobutyrivibrio such as strain OR35. Supplementary Fig. S1, available with the online version of this paper, shows the relationships between the 16S rDNA sequence of $P$. ruminis strain $0 / 10$ and closely related species, some of which were used for analyses in this study.

\section{Isolation of promoter fragments from $\boldsymbol{P}$. ruminis}

Plasmid pBK6 (Fig. 1) transforms both E. coli and $P$. ruminis. Of the $173,0.4-0.6 \mathrm{~kb}$ fragments of $P$. ruminis genomic DNA (total $88.8 \mathrm{~kb}$ ) screened for promoter activity, promoters $6,10,18,38$ and 46 were identified 
by the conversion of transformants to the Erm ${ }^{\mathrm{r}}$ phenotype. Replicate experiments resulted in the isolation of promoter 54 , which differed by one base pair from promoter 18 . The effectiveness of the bacteriophage T4D gene 32 transcription/translation terminator (Prentki \& Krisch, 1984) in preventing significant read-through transcription of the selectable marker gene (ermAM) was shown by the absence of $\mathrm{Erm}^{\mathrm{r}}$ transformants from the plasmid in the absence of 'promoter' inserts.

\section{Validation of primer extension analysis: identification of blaA transcription start site}

To correct migration anomalies caused by the presence of different fluorescent moieties on reverse transcripts compared to DNA sequencing products, the electrophoretic migration of precisely defined products amplified from pUC18 was used to derive equations 1 and 2 (Table 2). To validate these equations, primer extension analysis of the well-defined blaA promoter was performed (Brosius et al., 1982). Priming sites within the blaA gene, selected to produce reverse transcripts of 119, 270 and 520 bp (Fig. 3), showed that results from either sequencing system could be corrected to map the $5^{\prime}$ base of blaA mRNA to within \pm one base.

\section{Identification of transcription start sites and consensus promoter sequences}

Transcription start sites were identified within promoters 10, 18, 38, 46 and 54 (Fig. 4). Promoter 38 contained two transcription start sites, corresponding to promoters $38 \mathrm{a}$ and 38b. A primer-extension product was not detected from promoter 6 . When aligned by transcription start sites, consensus sequences at which the nucleotide identity was consistent in $\geqslant 75 \%$ of promoters showed hexamer motifs for the -10 and -35 elements, corresponding to the DNAbinding motifs for RNA polymerase complexed with the $\sigma^{70}$ subunit (Wosten, 1998). Consensus sequences for -10 and -35 elements, TTGWMA and ATAATATW, respectively, were interspaced by $15-16 \mathrm{bp}$. The -10 consensus was extended one nucleotide either side of the standard hexamer (indicated in bold), and was 5-17 bp upstream of the transcriptional start. In four of the nine promoters examined a TG dinucleotide adjacent to the $5^{\prime} \mathrm{A}$ residue of the expanded -10 element may correspond to a further extended -10 or -16 motif (Burr et al., 2000; Wosten, 1998).

Analysis using MEME identified a number of statistically significant, common motifs (POSITION $P$ value $<0.0001$ ). However, none were common to all promoters or in a consistent position relative to a transcription start site.

\section{Quantitative measurement of expression from cloned promoters in $\boldsymbol{P}$. ruminis}

Results from RT-qPCR for gusA transcript and GUS activity assays for promoters $6,10,18,46$ and 54 showed

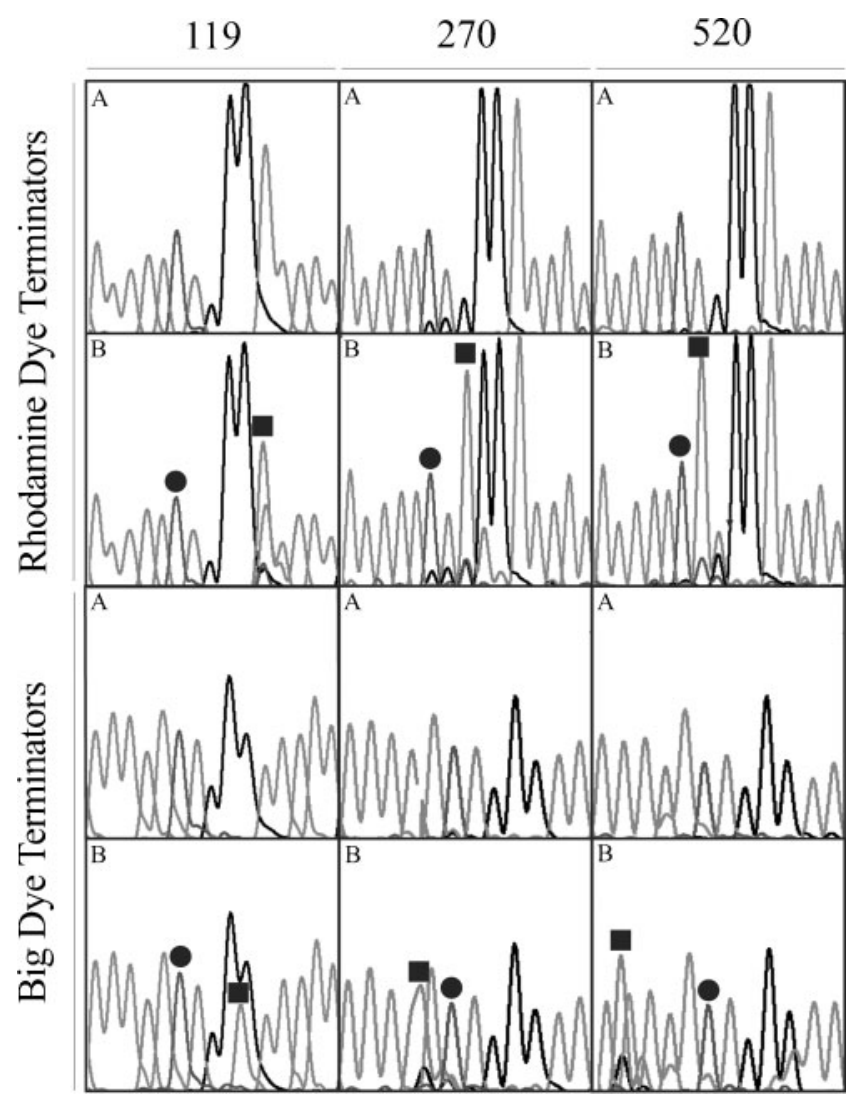

Fig. 3. Identification of the pUC18 blaA transcription start site. Columns: predicted size of cDNA (bp) primed using TSS1 (119), TSS2 (270) and TSS3 (520). (A) pUC18 sequence from primers TSS1, TSS2 or TSS3, (B) pUC18 sequence from the same primers, co-precipitated and electrophoresed with HEX-labelled primer extension products. Annotations show predicted (O) and observed ( $\boldsymbol{\square})$ migration positions of HEX-labelled DNA molecules.

that transcript levels were not proportional to enzyme activity (Table 3). Relative values for gusA mRNA levels and $\beta$-glucuronidase activity, by promoter number, were $10>6>18>46>54$ and $10>18>46>6>54$ respectively (Fig. 5). RT-qPCR showed that plasmid copy number did not differ significantly among $P$. ruminis transformants harbouring variants of $\mathrm{pBGT}$ that contained different promoters (ANOVA; $P>0.05 ; n=2$ ).

\section{DISCUSSION}

The data reported here show -10 elements in P. ruminis and closely related species to be expanded from the conventional hexamer to an octamer: ATAATATW. This consensus can also be represented as AtAaTAta (capitals show $>85 \%$ conservation). Expansion of -10 elements has been observed in other eubacteria, although their composition may differ from those identified here (Barnell et al., 1992; Bayley et al., 2000; Malakooti et al., 1995; Patek 


\begin{tabular}{|c|c|c|c|c|c|c|c|c|c|c|c|c|c|c|c|c|c|c|}
\hline Prom. & $\mathrm{U}$ & JP & & & -3 & 35 & & & interspacer & $x-1$ & & & & 10 & & & & DIS \\
\hline 46 & $82 \% \mathrm{~A} / \mathrm{T}$ & ttaacaa & $\mathbf{T}$ & $\mathbf{T}$ & G & $\mathbf{T}$ & $\mathbf{T}$ & $\mathbf{A}$ & ttt--ttcaaggtctttg & $A$ & $\mathbf{T}$ & A & A & $\mathbf{T}$ & $\mathbf{A}$ & $\mathbf{T}$ & $\boldsymbol{A}$ & tgataag \\
\hline 18 & $748 \mathrm{~A} / \mathrm{T}$ & atacata & $\mathbf{T}$ & $\mathbf{T}$ & G & $\mathrm{C}$ & A & $\mathbf{A}$ & cctgaatgagaatcattt & $A$ & $\mathrm{C}$ & A & A & $\mathbf{T}$ & $\mathbf{A}$ & $\mathbf{T}$ & $A$ & $\operatorname{gcct} \underline{t}$ \\
\hline 10 & $78 \% \mathrm{~A} / \mathrm{T}$ & aaatca & $\mathbf{A}$ & $\mathbf{A}$ & G & A & $\mathrm{C}$ & A & gggactctcaaatatat & $A$ & $\mathbf{T}$ & $\mathbf{A}$ & A & $\mathbf{T}$ & $\mathbf{A}$ & $\mathbf{A}$ & $A$ & tatcga \\
\hline $38 \mathrm{~A}$ & $78 \% \mathrm{~A} / \mathrm{T}$ & aaagtgc & $\mathbf{T}$ & $\mathbf{T}$ & G & A & $\mathrm{C}$ & $\mathbf{A}$ & aag--caagctgctcatg & $A$ & $\mathrm{~T}$ & $\mathbf{A}$ & A & $\mathbf{T}$ & A & $\mathbf{T}$ & $A$ & aacgagt \\
\hline $38 \mathrm{~B}$ & $76 \% \mathrm{~A} / \mathrm{T}$ & aaacctg & $\mathbf{T}$ & $\mathbf{T}$ & G & A & C & $\mathbf{T}$ & ttg--tggtagtgggatg & $A$ & $\mathrm{~T}$ & $\mathbf{A}$ & $\mathbf{A}$ & $\mathbf{T}$ & $\mathbf{A}$ & $\mathbf{T}$ & $A$ & ctattcgtt \\
\hline rep & $86 \% \mathrm{~A} / \mathrm{T}$ & aattaaa & $\mathbf{T}$ & $\mathbf{T}$ & A & $\mathbf{T}$ & A & $\mathbf{A}$ & caaa-tgttgtaatctgt & $A$ & $\mathrm{~T}$ & $\mathbf{T}$ & A & $\mathbf{T}$ & $\mathbf{A}$ & A & $T$ & ttgttatagtcttgtta \\
\hline flaA2 & $60 \% \mathrm{~A} / \mathrm{T}$ & ttgtacc & $\mathbf{T}$ & $\mathbf{T}$ & $\mathbf{T}$ & A & C & A & atttaataaggtatacct & A & $\mathrm{C}$ & A & $\mathbf{T}$ & A & $\mathbf{A}$ & $\mathbf{T}$ & $T$ & ccaccttg \\
\hline thl & $72 \% \mathrm{~A} / \mathrm{T}$ & atacaca & $\mathbf{T}$ & $\mathbf{T}$ & G & A & A & $\mathbf{A}$ & agaa--aatgtagttgtg & $G$ & $\mathrm{~T}$ & $\mathbf{A}$ & G & $\mathbf{T}$ & $\mathbf{A}$ & $\mathbf{T}$ & $T$ & $\operatorname{ttca} \underline{c}$ \\
\hline & CONSENSL & & $\mathbf{T}$ & $\mathbf{T}$ & G & W & $\mathbf{M}$ & $\mathbf{A}$ & & $A$ & $\mathbf{T}$ & $\mathbf{A}$ & A & $\mathbf{T}$ & A & $\mathbf{T}$ & $W$ & \\
\hline & & & $\underline{7}$ & $\underline{7}$ & $\underline{6}$ & $\underline{7}$ & $\underline{7}$ & $\underline{7}$ & & 7 & 6 & $\underline{7}$ & $\underline{6}$ & $\underline{7}$ & $\underline{8}$ & $\underline{6}$ & $\underline{8}$ & \\
\hline & & & $\overline{8}$ & $\overline{8}$ & $\overline{8}$ & $\overline{8}$ & $\overline{8}$ & $\overline{8}$ & & $\overline{8}$ & 8 & $\overline{8}$ & $\overline{8}$ & $\overline{8}$ & $\overline{8}$ & $\overline{8}$ & $\overline{8}$ & \\
\hline
\end{tabular}

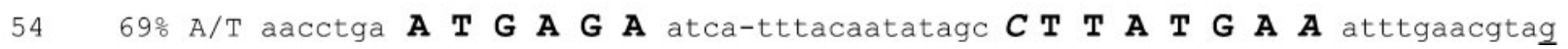

Fig. 4. Alignment of eight promoters identified in $P$. ruminis and closely related species. Promoters $10,18,38,46$ and 54 were isolated from $P$. ruminis strain $0 / 10$ or OR38. Promoter 38 contained two transcription start sites, corresponding to promoters $38 \mathrm{a}$ and $38 \mathrm{~b}$. For comparison, transcription start sites are shown (below the line) for promoters of $B$. fibrisolvens Bu49 rep (Hefford et al., 1997), Pseudobutyrivibrio sp. OR77 flaA-2 (Beard et al., 2000) and Pseudobutyrivibrio sp. OB156 thl (Asanuma et al., 2003). Transversion in the -35 element from a $T$ in promoter 18 to an A in promoter 54 is shown by shading. Transcription start sites are underlined. The -10 and -35 elements are in bold capitals. Possible extensions of the -10 element are in bold, italic capitals and have been incorporated into the consensus sequence. Possible further extensions to -10 elements $(E X-10)$ are in bold and incorporate the first base of the conserved (capitalized) -10 region. The A/T-rich region $50 \mathrm{bp}$ upstream of the -35 element is shown. Consensus sequences are shown at the bottom of the figure, with the frequencies of consensus nucleotides displayed beneath their respective positions.

et al., 2003). In all promoters studied here at least four positions within the -35 element, TTGWMA, matched the E. coli consensus, TTGACA (Lisser \& Margalit, 1993). The -35 element was less well conserved than the -10 element. The spacer between the -10 and -35 elements (16-18 bp) showed a narrow range compared to those of species such as Bacteroides fragilis (10-20 bp; Bayley et al., 2000),

Table 3. Comparison of mean promoter activities in $P$. ruminis after $6 \mathrm{~h}$ growth using RT-qPCR to measure mRNA levels, and GUS assay to measure $\beta$-glucuronidase levels

Groups with the same letter are not significantly different using the Tukey-Kramer (TK) Test $(\alpha<0.05)$. Promoters with the same superscript numbers had significantly different activities (Student's $t$ test; $P<0.05)$.

\begin{tabular}{|c|c|c|}
\hline Promoter & gusA mRNA level & $\beta$-Glucuronidase level \\
\hline 10 & A & A \\
\hline 18 & $\mathrm{~B}^{1,2}$ & A \\
\hline 46 & B & A \\
\hline 6 & B & $\mathrm{B}^{3,4}$ \\
\hline 54 & $\mathrm{~B}^{1}$ & $\mathrm{~B}^{3,5}$ \\
\hline None $^{*}$ & $\mathrm{~B}^{2}$ & $\mathrm{~B}^{4,5}$ \\
\hline
\end{tabular}

${ }^{\star}$ Negative control, plasmid pBGT containing a promoterless gus $A$ gene.
Helicobacter pylori (19-23 bp; Vanet et al., 2000), although it was similar to that of others such as Corynebacterium glutamicum (16-18 bp; Patek et al., 2003) and Lactobacillus sp. (16-19 bp; McCracken et al., 2000). Using this shotgun approach, the isolation of promoters that bind the primary sigma factor of $P$. ruminis was considered to be likely as it has been estimated that over $80 \%$ of promoters in E. coli are regulated by the primary $\sigma^{70}$ factor (Ishihama, 2000) and a similar situation is likely to apply to promoters of other species.

Promoters 38a, 38b and 46 contained an extended -10 element (EX -10), with a TGN motif upstream of the standard hexamer. This motif is present in approximately $20 \%$ of E. coli promoters (Burr et al., 2000; Sanderson et al., 2003 ) and in up to $60 \%$ of genes from Gram-positive bacteria such as Streptococcus pneumoniae, Clostridium pasteurianum and Bacillus subtilis (Agarwal \& Tyagi, 2003). In E. coli the EX -10 is generally associated with lack of an identifiable -35 element (Belyaeva et al., 1993; Chan \& Busby, 1989; Keilty \& Rosenberg, 1987). However, in this and other studies (Sabelnikov et al., 1995; Voskuil \& Chambliss, 1998), the TG dinucleotide directly upstream of the -10 element was associated with highly conserved -10 and -35 elements. The expanded EX -10 motif observed in B. subtilis (TRTGN; Helmann, 1995; Voskuil \& Chambliss, 2002) was not apparent in the species studied here. The frequency of the EX -10 element in P. ruminis 


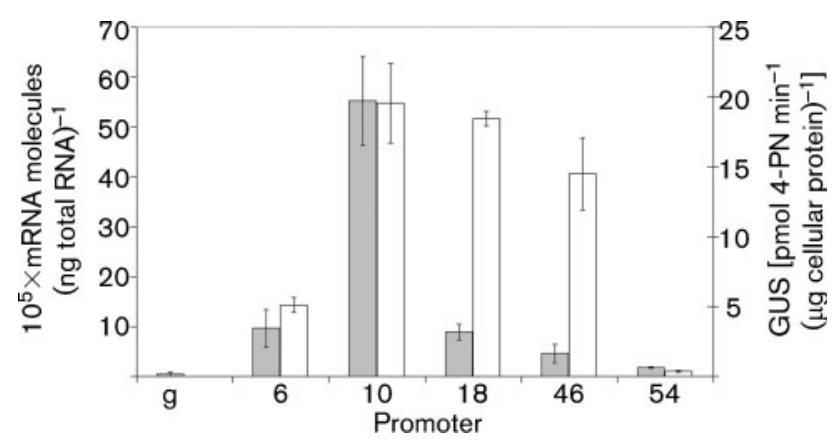

Fig. 5. Promoter strengths expressed from variants of vector pBGT in $P$. ruminis 0/10. Grey columns, gus $A$ transcript copy number (shown on left axis). Errror bars represent SD $(n=2)$. White columns, $\beta$-glucuronidase activity (shown on right axis). Error bars represent SEM $(n=3)$. g, control variant of $\mathrm{pBGT}$, without a promoter directly upstream of the gus $A$ gene.

and closely related species cannot be inferred from this study, because it may vary between species of the same genus. For example, it has been shown that the TG motif was present in $54 \%$ of promoters in some species of Lactobacillus, but was not significantly represented in others (McCracken et al., 2000).

The UP element is an AT-rich region upstream of the -35 element. No match was found in these ruminal species for the E. coli UP element consensus (Estrem et al., 1998). However, there was a marked reduction in GC content directly upstream of the -35 element, which may influence DNA curvature and transcription initiation (Gabrielian et al., 1999). Computational analysis of these promoter regions did not reveal any previously uncharacterized motifs.

The lack of correlation between the relative abundance of mRNA and of gene product seen in this study has previously been reported in other studies (Bannantine et al., 1997; Glanemann et al., 2003; Niehus et al., 2002; Rosado \& Gage, 2003). Plasmid pBG constructs all shared a common $103 \mathrm{nt}$ leader sequence upstream of the gusA gene and any differences in mRNA stability could not be attributed to different lengths or sequences of the $5^{\prime}$ untranslated region. It has been shown that the activity of a single promoter, as reported by various proteins, can vary greatly (Kahala \& Palva, 1999; Niehus et al., 2002). Among those studies, only the luciferase system accurately reported the relationship between mRNA and gene product levels. It is possible that disparity between mRNA and $\beta$-glucuronidase levels is related to the stability of $\beta$-glucuronidase in P. ruminis.

No correlation was found between promoter sequence and transcriptional activity. Promoter activity is likely to be affected by the composition and relative positions of elements within promoter regions, and other factors such as gene-specific activators and repressors (Lloyd et al.,
2001; Rhodius \& Busby, 1998; Rojo, 2001), ppGpp (Barker et al., 2001; Chatterji \& Ojha, 2001), termination and antitermination factors (Henkin, 1996; Henkin \& Yanofsky, 2002), anti-sigma factors (Helmann, 1999), NTP concentration (Schneider et al., 2002), transcript cleavage factors (Hsu et al., 1995) and factor-dependent DNA curvature or torsional state (Dai \& Rothman-Denes, 1999; Xu \& Hoover, 2001). Indeed computational analysis (data not shown) suggests that promoter 46 may be regulated by NarL/NarP (Dong et al., 1992; Householder et al., 1999; Li \& Stewart, 1992) and promoter 10 contained five repetitive elements that may act as binding motifs for regulatory proteins.

Due to the promoter-rescue plasmid-based experimental approach employed in this study, it was not possible to identify the genes directly downstream from the promoters, within the $P$. ruminis genome. The activity of these promoters in the $P$. ruminis genome is putative. Their usefulness in expressing newly introduced, plasmid-borne genes is clear from the data presented here. Gene(s) under the control of specific promoter sequences, flanking the promoters, could be identified using techniques similar to those used to identify genomic sequences flanking inserted transposons (Kwon \& Ricke, 2000). Identification of these genes would allow genome-derived transcript levels to be measured using RT-qPCR, to confirm that these promoters do indeed initiate transcription from the genome.

A single-base difference between the -35 elements of promoters 18 and 54 resulted in the recognition of different consensus regions by RNA polymerase (Fig. 4) and promoter 54 showed significantly lower activity than promoter 18 . The mutation may have reduced recruitment to promoter 54, or may have enhanced recruitment but reduced promoter escape due to strong -35 elementpolymerase interactions. Interestingly, elements of promoter 54 did not resemble the consensus sequences derived in this study, and consensus-like promoter architecture is likely to be essential for both optimal RNA polymerase recruitment and escape.

In future studies, investigation of the interplay between transcription and translation could be extended by performing assays of both processes in parallel, allowing direct correlation between reporter protein accumulation and transient mRNA levels (Glanemann et al., 2003). The promoter reporter plasmid constructed in this study is useful for the quick identification of strong promoters for high-level expression of exogenous genes in P. ruminis, such as promoter 10. Specifically, such promoters may be used for the high-level expression of fluoroacetate dehalogenase, an enzyme produced by recombinant $B$. fibrisolvens in the rumen to detoxify the plant poison fluoroacetate (Gregg et al., 1998).

The development and implementation of tools for the study of promoters in $P$. ruminis has allowed the characterization of novel promoters and has laid the foundation for future studies of a larger subset of 
promoters from this bacterium. The investigation of promoters in a standard context, as provided for by these tools, will benefit future studies of active RNA polymerase DNA-binding motifs to determine whether consensus sequences derived in this study are representative of the species.

\section{ACKNOWLEDGEMENTS}

Many thanks to Frances Brigg of the State Agricultural Biotechnology Centre Sequencing Service for helpful discussions and technical advice. Plasmids pFUS1 and pHP45 $\omega$ were kindly supplied by Dr Wayne Reeve (Center For Rhizobium Studies, Murdoch University). Research was performed at the State Agricultural Biotechnology Centre, Murdoch University, and was funded by Murdoch University.

\section{REFERENCES}

Agarwal, N. \& Tyagi, A. K. (2003). Role of $5^{\prime}$-TGN-3' motif in the interaction of mycobacterial RNA polymerase with a promoter of 'extended -10' class. FEMS Microbiol Lett 225, 75-83.

Asanuma, N., Kawato, M., Ohkawara, S. \& Hino, T. (2003). Characterization and transcription of the genes encoding enzymes involved in butyrate production in Butyrivibrio fibrisolvens. Curr Microbiol 47, 203-207.

Bailey, T. L. \& Gribskov, M. (1998). Combining evidence using pvalues: application to sequence homology searches. Bioinformatics 14, 48-54.

Bannantine, J. P., Barletta, R. G., Thoen, C. O. \& Andrews, R. E., Jr (1997). Identification of Mycobacterium paratuberculosis gene expression signals. Microbiology 143, 921-928.

Barker, M. M., Gaal, T., Josaitis, C. A. \& Gourse, R. L. (2001). Mechanism of regulation of transcription initiation by ppGpp. I. Effects of ppGpp on transcription initiation in vivo and in vitro. J Mol Biol 305, 673-688.

Barnell, W. O., Liu, J., Hesman, T. L., O'Neill, M. C. \& Conway, T. (1992). The Zymomonas mobilis $g l f, z w f$, edd, and $g l k$ genes form an operon: localization of the promoter and identification of a conserved sequence in the regulatory region. J Bacteriol 174, 2816-2823.

Bayley, D. P., Rocha, E. R. \& Smith, C. J. (2000). Analysis of cepA and other Bacteroides fragilis genes reveals a unique promoter structure. FEMS Microbiol Lett 193, 149-154.

Beard, C. E., Hefford, M. A., Forster, R. J., Sontakke, S., Teather, R. M. \& Gregg, K. (1995). A stable and efficient transformation system for Butyrivibrio fibrisolvens OB156. Curr Microbiol 30, 105-109.

Beard, C. E., Gregg, K., Kalmokoff, M. \& Teather, R. M. (2000). Construction of a promoter-rescue plasmid for Butyrivibrio fibrisolvens and its use in characterization of a flagellin promoter. Curr Microbiol 40, 164-168.

Belyaeva, T., Griffiths, L., Minchin, S., Cole, J. \& Busby, S. (1993). The Escherichia coli cys $G$ promoter belongs to the 'extended -10 ' class of bacterial promoters. Biochem J 296, 851-857.

Box, G. E. P., Hunter, W. G. \& Hunter, J. S. (1978). Statistics for Experimenters. New York: John Wiley \& Sons.

Breslauer, K. J., Frank, R., Blocker, H. \& Marky, L. A. (1986). Predicting DNA duplex stability from the base sequence. Proc Natl Acad Sci U S A 83, 3746-3750.

Brooker, J. D., Lockington, R. A., Attwood, G. T., Langridge, P., Nield, J. K. \& Langridge, U. (1989). Engineering ruminal flora for improved protein quality. In The Biology of Wool and Hair, pp.
425-440. Edited by G. E. Rogers, P. J. Reis, K. A. Ward \& R. C. Marshal. London: Chapman \& Hall.

Brosius, J., Cate, R. L. \& Perlmutter, A. P. (1982). Precise location of two promoters for the $\beta$-lactamase gene of pBR322. S1 mapping of ribonucleic acid isolated from Escherichia coli or synthesized in vitro. J Biol Chem 257, 9205-9210.

Burr, T., Mitchell, J., Kolb, A., Minchin, S. \& Busby, S. (2000). DNA sequence elements located immediately upstream of the -10 hexamer in Escherichia coli promoters: a systematic study. Nucleic Acids Res 28, 1864-1870.

Bustin, S. A. (2000). Absolute quantification of mRNA using realtime reverse transcription polymerase chain reaction assays. $\mathrm{J} \mathrm{Mol}$ Endocrinol 25, 169-193.

Chan, B. \& Busby, S. (1989). Recognition of nucleotide sequences at the Escherichia coli galactose operon P1 promoter by RNA polymerase. Gene 84, 227-236.

Chatterji, D. \& Ojha, A. K. (2001). Revisiting the stringent response, ppGpp and starvation signaling. Curr Opin Microbiol 4, 160-165.

Dai, X. \& Rothman-Denes, L. B. (1999). DNA structure and transcription. Curr Opin Microbiol 2, 126-130.

Dong, X. R., Li, S. F. \& DeMoss, J. A. (1992). Upstream sequence elements required for NarL-mediated activation of transcription from the narGHJI promoter of Escherichia coli. J Biol Chem 267, 14122-14128.

Dower, W. J., Miller, J. F. \& Ragsdale, C. W. (1988). High efficiency transformation of E. coli by high voltage electroporation. Nucleic Acids Res 16, 6127-6145.

Estrem, S. T., Gaal, T., Ross, W. \& Gourse, R. L. (1998). Identification of an UP element consensus sequence for bacterial promoters. Proc Natl Acad Sci U S A 95, 9761-9766.

Felsenstein, J. (1989). PHYLIP - Phylogeny inference package (version 3.2). Cladistics 5, 164-166.

Forster, R. J., Teather, R. M., Gong, J. \& Deng, S. J. (1996). 16S rDNA analysis of Butyrivibrio fibrisolvens: phylogenetic position and relation to butyrate-producing anaerobic bacteria from the rumen of whitetailed deer. Lett Appl Microbiol 23, 218-222.

Gaal, T., Ross, W., Estrem, S. T., Nguyen, L. H., Burgess, R. R. \& Gourse, R. L. (2001). Promoter recognition and discrimination by $\mathrm{E} \sigma^{\mathrm{s}}$ RNA polymerase. Mol Microbiol 42, 939-954.

Gabrielian, A. E., Landsman, D. \& Bolshoy, A. (1999). Curved DNA in promoter sequences. In Silico Biol 1, 183-196.

Ghosh, D. (1998). OOTFD (Object-Oriented Transcription Factors Database): an object-oriented successor to TFD. Nucleic Acids Res 26, 360-362.

Ghosh, D. (2000). Object-oriented transcription factors database (ooTFD). Nucleic Acids Res 28, 308-310.

Gibson, T. J. (1984). Studies on the Epstein-Barr Virus Genome. $\mathrm{PhD}$ thesis, University of Cambridge.

Glanemann, C., Loos, A., Gorret, N., Willis, L. B., O'Brien, X. M., Lessard, P. A. \& Sinskey, A. J. (2003). Disparity between changes in mRNA abundance and enzyme activity in Corynebacterium glutamicum: implications for DNA microarray analysis. Appl Microbiol Biotechnol 61, 61-68.

Gregg, K. \& Sharpe, H. (1991). Enhancement of rumen microbial detoxification by gene transfer. In Physiological Aspects of Digestion and Metabolism in Ruminants: Proceedings of the Seventh International Symposium of Ruminant Physiology, pp. 719-735. San Diego: Academic Press.

Gregg, K., Bauchop, T., Hudman, J. F., Vercoe, P. E., Ware, C. E., Woods, J. R. \& Leng, R. A. (1987). Application of recombinant DNA methods to rumen bacteria. In Recent Advances in Animal Nutrition in 
Australia 1987, pp. 112-120. Edited by D. J. Farrell. Arimdale: University of New England.

Gregg, K., Cooper, C. L., Schafer, D. J., Sharpe, H., Beard, C. E., Allen, G. \& Xu, J. (1994). Detoxification of the plant toxin fluoroacetate by a genetically modified rumen bacterium. Biotechnology (N Y) 12, 1361-1365.

Gregg, K., Hamdorf, B., Henderson, K., Kopecny, J. \& Wong, C. (1998). Genetically modified ruminal bacteria protect sheep from fluoroacetate poisoning. Appl Environ Microbiol 64, 3496-3498.

Hefford, M. A., Kobayashi, Y., Allard, S. E., Forster, R. J. \& Teather, R. M. (1997). Sequence analysis and characterization of pOM1, a small cryptic plasmid from Butyrivibrio fibrisolvens, and its use in construction of a new family of cloning vectors for butyrivibrios. Appl Environ Microbiol 63, 1701-1711.

Helmann, J. D. (1995). Compilation and analysis of Bacillus subtilis $\sigma^{\mathrm{A}}$-dependent promoter sequences: evidence for extended contact between RNA polymerase and upstream promoter DNA. Nucleic Acids Res 23, 2351-2360.

Helmann, J. D. (1999). Anti-sigma factors. Curr Opin Microbiol 2, 135-141.

Henkin, T. M. (1996). Control of transcription termination in prokaryotes. Annu Rev Genet 30, 35-57.

Henkin, T. M. \& Yanofsky, C. (2002). Regulation by transcription attenuation in bacteria: how RNA provides instructions for transcription termination/antitermination decisions. Bioessays 24, 700-707.

Householder, T. C., Belli, W. A., Lissenden, S., Cole, J. A. \& Clark, V. L. (1999). cis- and trans-acting elements involved in regulation of aniA, the gene encoding the major anaerobically induced outer membrane protein in Neisseria gonorrhoeae. J Bacteriol 181, 541-551.

Hsu, L. M., Vo, N. V. \& Chamberlin, M. J. (1995). Escherichia coli transcript cleavage factors GreA and GreB stimulate promoter escape and gene expression in vivo and in vitro. Proc Natl Acad Sci U S A 92, 11588-11592.

Ishihama, A. (2000). Functional modulation of Escherichia coli RNA polymerase. Annu Rev Microbiol 54, 499-518.

Kahala, M. \& Palva, A. (1999). The expression signals of the Lactobacillus brevis slpA gene direct efficient heterologous protein production in lactic acid bacteria. Appl Microbiol Biotechnol 51, 71-78.

Kalmokoff, M. L., Lu, D., Whitford, M. F. \& Teather, R. M. (1999). Evidence for production of a new lantibiotic (butyrivibriocin OR79A) by the ruminal anaerobe Butyrivibrio fibrisolvens OR79: characterization of the structural gene encoding butyrivibriocin OR79A. Appl Environ Microbiol 65, 2128-2135.

Kalmokoff, M. L., Allard, S., Austin, J. W., Whitford, M. F. \& Hefford, M. A. (2000). Biochemical and genetic characterization of the flagellar filaments from the rumen anaerobe Butyrivibrio fibrisovlens OR77. Anaerobe 6, 93-109.

Keilty, S. \& Rosenberg, M. (1987). Constitutive function of a positively regulated promoter reveals new sequences essential for activity. J Biol Chem 262, 6389-6395.

Kimura, M. (1980). A simple method for estimating evolutionary rates of base substitutions through comparative studies of nucleotide sequences. J Mol Evol 16, 111-120.

Klieve, A. V., Hudman, J. F. \& Bauchop, T. (1989). Inducible bacteriophages from ruminal bacteria. Appl Environ Microbiol 55, 1630-1634.

Kobayashi, Y., Forster, R. J. \& Teather, R. M. (2000). Development of a competitive polymerase chain reaction assay for the ruminal bacterium Butyrivibrio fibrisolvens OB156 and its use for tracking an OB156-derived recombinant. FEMS Microbiol Lett 188, 185-190.
Kopecny, J., Logar, R. M. \& Kobayashi, Y. (2001). Phenotypic and genetic data supporting reclassification of Butyrivibrio fibrisolvens isolates. Folia Microbiol (Praha) 46, 45-48.

Kopecny, J., Zorec, M., Mrazek, J., Kobayashi, Y. \& Marinsek-Logar, R. (2003). Butyrivibrio hungatei sp. nov. and Pseudobutyrivibrio xylanivorans sp. nov., butyrate-producing bacteria from the rumen. Int J Syst Evol Microbiol 53, 201-209.

Kwon, Y. M. \& Ricke, S. C. (2000). Efficient amplification of multiple transposon-flanking sequences. J Microbiol Methods 41, 195-199.

Li, J. \& Stewart, V. (1992). Localization of upstream sequence elements required for nitrate and anaerobic induction of $f d n$ (formate dehydrogenase-N) operon expression in Escherichia coli K-12. J Bacteriol 174, 4935-4942.

Lisser, S. \& Margalit, H. (1993). Compilation of E. coli mRNA promoter sequences. Nucleic Acids Res 21, 1507-1516.

Lloyd, G., Landini, P. \& Busby, S. (2001). Activation and repression of transcription initiation in bacteria. Essays Biochem 37, 17-31.

Mackie, R. I. \& White, B. A. (1990). Recent advances in rumen microbial ecology and metabolism: potential impact on nutrient output. J Dairy Sci 73, 2971-2995.

Malakooti, J., Wang, S. P. \& Ely, B. (1995). A consensus promoter sequence for Caulobacter crescentus genes involved in biosynthetic and housekeeping functions. J Bacteriol 177, 4372-4376.

McCracken, A., Turner, M. S., Giffard, P., Hafner, L. M. \& Timms, P. (2000). Analysis of promoter sequences from Lactobacillus and Lactococcus and their activity in several Lactobacillus species. Arch Microbiol 173, 383-389.

Misener, S. \& Krawetz, S. (2000). Bioinformatics Methods and Protocols: Methods in Molecular Biology. Totowa: Humana Press.

Niehus, E., Ye, F., Suerbaum, S. \& Josenhans, C. (2002). Growth phase-dependent and differential transcriptional control of flagellar genes in Helicobacter pylori. Microbiology 148, 3827-3837.

Patek, M., Nesvera, J., Guyonvarch, A., Reyes, O. \& Leblon, G. (2003). Promoters of Corynebacterium glutamicum. J Biotechnol 104, 311-323.

Petersen, L., Larsen, T. S., Ussery, D. W., On, S. L. \& Krogh, A. (2003). $r p o D$ promoters in Campylobacter jejuni exhibit a strong periodic signal instead of a -35 box. J Mol Biol 326, 1361-1372.

Prentki, P. \& Krisch, H. M. (1984). In vitro insertional mutagenesis with a selectable DNA fragment. Gene 29, 303-313.

Reeve, W. G., Tiwari, R. P., Worsley, P. S., Dilworth, M. J., Glenn, A. R. \& Howieson, J. G. (1999). Constructs for insertional mutagenesis, transcriptional signal localization and gene regulation studies in root nodule and other bacteria. Microbiology 145, 1307-1316.

Reeve, W. G., Tiwari, R. P., Kale, N. B., Dilworth, M. J. \& Glenn, A. R. (2002). ActP controls copper homeostasis in Rhizobium leguminosarum bv. viciae and Sinorhizobium meliloti preventing low $\mathrm{pH}-$ induced copper toxicity. Mol Microbiol 43, 981-991.

Rhodius, V. A. \& Busby, S. J. (1998). Positive activation of gene expression. Curr Opin Microbiol 1, 152-159.

Rogers, G. E. (1990). Improvement of wool production through genetic engineering. Trends Biotechnol 8, 6-11.

Rojo, F. (2001). Mechanisms of transcriptional repression. Curr Opin Microbiol 4, 145-151.

Rosado, M. \& Gage, D. J. (2003). Transcriptional control of a rRNA promoter of the nodulating symbiont Sinorhizobium meliloti. FEMS Microbiol Lett 226, 15-22.

Sabelnikov, A. G., Greenberg, B. \& Lacks, S. A. (1995). An extended -10 promoter alone directs transcription of the DpnII operon of Streptococcus pneumoniae. J Mol Biol 250, 144-155. 
Saitou, N. \& Nei, M. (1987). The neighbor-joining method: a new method for reconstructing phylogenetic trees. Mol Biol Evol 4, 406-425.

Sanderson, A., Mitchell, J. E., Minchin, S. D. \& Busby, S. J. (2003). Substitutions in the Escherichia coli RNA polymerase $\sigma^{70}$ factor that affect recognition of extended -10 elements at promoters. FEBS Lett 544, 199-205.

Schneider, D. A., Gaal, T. \& Gourse, R. L. (2002). NTP-sensing by rRNA promoters in Escherichia coli is direct. Proc Natl Acad Sci U S A 99, 8602-8607.

Smith, C. J. \& Hespell, R. B. (1983). Symposium: application of molecular genetics in ruminants. Prospects for development and use of recombinant DNA techniques with ruminal bacteria. J Dairy Sci 66, 1536-1546.

Tatusova, T. A. \& Madden, T. L. (1999). BLAST 2 Sequences, a new tool for comparing protein and nucleotide sequences. FEMS Microbiol Lett 174, 247-250.

Teather, R. M. (1985). Application of genetic manipulation to rumen microflora. Can J Anim Sci 65, 563-574.

Teather, R. M. \& Forster, R. J. (1998). Manipulating the rumen microflora with bacteriocins to improve ruminant production. Can J Anim Sci 78, 57-69.

Thompson, J. D., Gibson, T. J., Plewniak, F., Jeanmougin, F. \& Higgins, D. G. (1997). The CLUSTAL_X Windows interface: flexible strategies for multiple sequence alignment aided by quality analysis tools. Nucleic Acids Res 25, 4876-4882.

Vanet, A., Marsan, L., Labigne, A. \& Sagot, M. F. (2000). Inferring regulatory elements from a whole genome. An analysis of Helicobacter pylori $\sigma^{80}$ family of promoter signals. J Mol Biol 297, 335-353.

Vogel, J., Axmann, I. M., Herzel, H. \& Hess, W. R. (2003). Experimental and computational analysis of transcriptional start sites in the cyanobacterium Prochlorococcus MED4. Nucleic Acids Res 31, 2890-2899.

Voskuil, M. I. \& Chambliss, G. H. (1998). The -16 region of Bacillus subtilis and other Gram-positive bacterial promoters. Nucleic Acids Res 26, 3584-3590.

Voskuil, M. I. \& Chambliss, G. H. (2002). The TRTGn motif stabilizes the transcription initiation open complex. J Mol Biol 322, 521-532.

Weiner, J., III, Herrmann, R. \& Browning, G. F. (2000). Transcription in Mycoplasma pneumoniae. Nucleic Acids Res 28, 4488-4496.

Woods, J. R., Hudman, J. F. \& Gregg, K. (1989). Isolation of an endoglucanase gene from Bacteroides ruminicola subsp. brevis. J Gen Microbiol 135, 2543-2549.

Wosten, M. M. (1998). Eubacterial sigma-factors. FEMS Microbiol Rev 22, 127-150.

Xu, H. \& Hoover, T. R. (2001). Transcriptional regulation at a distance in bacteria. Curr Opin Microbiol 4, 138-144.

Edited by: H. J. Strobel 